\title{
20
}

\section{Getting Administrative Support for Your Project}

\author{
Joan Middendorf \\ Indiana University
}

For faculty development professionals to succeed with projects, we need the belp of key administrators. More than anyone else, they can link our efforts to campus priorities, belp us understand the decision-making system, and facilitate our efforts. This essay describes six steps for gaining and maintaining administrative support for projects. The steps entail 1) knowing administrator needs, 2) identifying likely supporters, 3) maintaining good working relationships, 4) involving the sponsors, 5) evaluating the sponsors' commitment, and 6) recognizing the support of sponsors. Collaboration with administrators and application of the stages is illustrated with a case study of Indiana University's Freshman Learning Project.

\section{INTRODUCTION}

For faculty development professionals to succeed with projectswhether in getting faculty to accept new teaching approaches or any other change-we need the help of key administrators. More than anyone else, they can link our efforts to campus priorities and help us understand the decision-making system. Through their knowledge, influence, and resources, they can provide support for our project. But, how do we get administrators to provide this kind of support? We need to clarify for ourselves what we need from them and identify which of them can best give what our project needs. Then, we focus - with understanding, respect, and recognition-on their concerns, needs, and goals.

While we usually can clarify what we need and who we should involve, we often fail to truly understand the viewpoints of those we ask for help. Loaded down with project meetings, seminars, materials develop- 
ment, and other details, we often ask for administrative support without recognizing the administrators' perspectives, responding to their concerns, or providing recognition for their contributions. Only by getting in the other person's shoes-even when he or she is an administratorcan we move toward a truly collaborative and successful project. Several administrators give their advice on how to make a program successful.

\section{Administrators on Getring SuPport}

At the 1999 POD Conference session, "Getting Administrative Support for Your Project," three POD leaders gave their advice for getting administrative support.

- Steve Richardson, Vice President for Academic Affairs, Winona State University:

"If you make the administrators look good, they will give you additional support." "You have to make your program have visibility and credibility."

- Joan North, Dean, College of Professional Studies, University of Wisconsin-Stevens Point:

"The closer in rank you are to the person you want support from, the more likely you will get the support you need."

- Mary Deane Sorcinelli, Associate Provost for Faculty Development, University of Massachusetts at Amherst:

"Your programs should be viewed by faculty as enrichment rather than remedial. Listen to the faculty and administrators, be responsive, and make connections."

Moreover, by aligning our work with the higher-level perspective of administrators, our efforts can become more strategic. If we assume that we know the goals of administrators or that we know what is best for the faculty, our efforts may be off target. We may not spell out our expectations, or we may fail to fit them in with the university planning process.

This essay is the third in a series that draws useful principles from the literature on planned change to enhance the work of faculty developers. For a thorough understanding of the literature on planned change, see Rogers (1995), Havelock (1995), and Dormant (1999). Also, Guskin $(1994,1996)$ discusses the kinds of changes universities face and the restructuring that will be necessitated. The first essay in this three-part series 
explains the stages faculty move through in accepting a change, and the strategies we can use to enhance adoption (Middendorf, 1998). The second essay explains the different rates at which faculty accept change and then identifies the faculty most likely to lead their colleagues to accepting new approaches (Middendorf, 1999). This, the third essay, begins with a case study of Indiana University's Freshman Learning Project, and describes six steps for enhancing collaboration between faculty developers and administrators. It is followed by a worksheet for planning ways to get administrative support for your project. This can be used by a planning team before potential sponsors are contacted to increase chances for success.

\section{A Case Study-The Freshman Learning Project}

The Indiana University Freshman Learning Project (FLP) supports faculty to find new ways to help students learn more in large introductory courses. The program rests on the assumption that the process of rethinking approaches to teaching is best done within a community of teachers and is best disseminated within that same community. Each year FLP develops a cohort of faculty leaders committed to student learning. The program began with a three-year grant of $\$ 379,233$ from the president of Indiana University. The grant was awarded as the result of a competitive proposal process. It includes a $\$ 5,000$ stipend for each faculty participant, as well as an annual course release for the faculty member who co-directs the project.

Annual activities commence with interviews to determine the basic skills and knowledge the faculty teach. This is followed by team building and an informal assessment of roadblocks to learning. In a two-week summer session, faculty study the literature on successful developments in teaching and learning, and they design innovative lessons which they present to the group. The FLP coordinates the activities of these fellows in subsequent years as they meet to discuss the implementation of new teaching strategies in their classes and bring new ideas about pedagogy to the attention of their colleagues.

The positive impact of the program has been manifested in specific innovations in the fellows' classrooms and in their efforts to influence both their colleagues and the institution. For example, one fellow has subsequently become the Associate Dean for Undergraduate Education in the College of Arts and Sciences, a second has become the first faculty member ever to sit on the campus Classroom Design Committee and has taken a more active role on the Bloomington faculty council, and a third played an important role in the College Committee for Undergraduate 
Education. Another fellow has created an internet network of instructors in his field and is organizing a seminar for his department to discuss the ideas raised by the FLP. Three of the second-year fellows have already presented innovative model lessons to diverse faculty groups, such as the new faculty orientation. Additionally, Indiana University's president met with the fellows and, after hearing their praise for the transformative experience, provided significant additional funds.

The FLP model thrives because of three key aspects: 1) careful selection of participants, 2) exposure to the scholarship of teaching and learning, and 3) the creation of a tightly linked cohort of fellows who translate new ideas into practice. But to get to this success, the support of administrators was critical. Following are six steps for gaining and maintaining administrative support for a change project such as FLP.

\section{Step 1: Know What the Administrators Need}

For all the leaders involved in a project to pull toward the same goals, they must be clear about the concerns of administrators. In interviews, the author asked six university administrators what they looked for in a project they were likely to support. Three themes emerged: compatibility with priorities, buy-in, and widespread influence. Administrators wanted to know the answers to these questions.

\section{Compatibility witb institutional priorities}

- How does this project fit in with the institutional mission?

- Is the project's goal compatible with the priorities of the institution?

- How much will it cost?

\section{Buy-in from faculty and staff}

- How will the faculty and staff be involved in planning?

- How will faculty and staff be involved in implementation?

\section{Widespread impact}

- Is this project worthwhile? How many people will it affect?

- Will the results be suitable for journal publication?

- Does it involve credible people whom others will follow?

Projects are more likely to be successful if they are aligned with campus priorities, have buy-in from those involved in implementation, and 
influence more than a few people. Each of these can be specifically planned for (see Appendix 20.1, Question 4).

\section{Step 2: Identify Likely Supporters}

An important step in a project's success is identifying administrators who will support it. The literature calls such a person a "sponsor: a person (or group) with the power and influence to legitimize your project and provide ongoing support" (Dormant, Middendorf, \& Marker, 1997). In the university, the ideal sponsor should be high enough in the administration to have power and resources, but not so high up that he or she would not have time to devote to the project. Depending on the size of the organization, we can recruit several layers of sponsors: low-level administrators who will help implement the project, mid-level administrators who will set policy and approve funds, and high-level administrators who will provide symbolic leadership. (In small schools the symbolic and policy levels may be combined.) In general, the lower level administrators are more actively engaged with the project, involving their high profile superiors as needed for impact.

University administrators tend to be extremely busy people whose efforts can be diluted by the sheer number of initiatives and committees they are involved in. How can we get from them the time and effort our new project requires? If we recruit sponsors whose priorities are aligned with the project or if we develop projects that are aligned with sponsor needs, we are more likely to get strong support for our projects.

To find our sponsors, the co-director of the FLP, Professor David Pace (Department of History), and I considered whose needs this project could serve. The Associate Dean for Undergraduate Education of the College of Arts and Sciences was responsible for implementing a new curriculum that involved large enrollment, introductory courses. We aimed the program at the many faculty who would teach the new curriculum. The Director of Instructional Support Services was interested in improving teaching at IU in general. We needed the resources he could provide (staff and computers) as much as he needed our project. So the FLP was mutually beneficial to both of these active sponsors. In turn, these two administrators kept their bosses (a dean and a vice chancellor) informed of the project, calling on them for specific help as needed.

\section{Step 3: Maintain Good Working Relationships}

Once the sponsors get on board, we must establish and maintain effective working relationships with them and other administrators in the uni- 
versity hierarchy. In this area, John Kotter's (1985) work on managing bosses can be translated into relations with sponsors and key administrators. Kotter recommends taking the time and effort to nurture relations with superiors by doing the following:

- Learn the administrator's preferred work style.

- Try to understand the administrator's strengths and weaknesses.

- Keep in mind our own personalities, strengths, and weaknesses (especially any sensitivities to supervision).

- Be absolutely clear about mutual expectations.

- Maintain the relationship by being straightforward and keeping the administrator informed.

In managing a project, instructional support personnel will work closely with sponsors and will also interact more tangentially with other administrators who are not directly involved in the project. These may be department chairs of faculty or the supervisors of staff who will implement the project. Depending on how closely tied they are to the program, they need to either be kept well informed or treated as sponsors.

Being sensitive to administrators' work style smoothes the working relationship. For instance, do they prefer to be briefed about the project via memo or through a face-to-face meeting? Do they prefer formal or informal meetings? Do they regard conflict as something to be avoided or as a source for additional ideas? Do they tend to delegate or micromanage? One sponsor of the FLP perceived some unintended criticisms of his staff in a few email messages. His perceptions changed for the better when we discussed the project in person and I then occasionally lunched with him to ensure the message received was the one intended.

As instructional consultants, we face different pressures than administrators do. We can help each other succeed by knowing each others' strengths and weaknesses. For example, if sponsors are quick to criticize and slow to praise, consultants can know not to take negative comments personally. Or if a consultant acknowledges he needs more background, a sponsor can provide it.

Knowing ourselves, particularly our temperament regarding authority figures, can facilitate interactions. Some people habitually resent or are frustrated by those in authority, while others become dependent on authority or compliant with supervisors. Knowing our potential 
reactions to collaborators in a position of higher authority can help us avoid unthinking reactions. Knowing our weaknesses and strengths can help us avoid our personal pitfalls and play to our strengths.

Ambiguity in expectations for anyone involved in a project can create conflict. By taking the time to put the project goals and individual responsibilities in writing, we provide a chance to clarify and negotiate differences of opinion. This then provides a framework to be sure people complete tasks as agreed. A sponsor can sour on a project if project directors are not dependable about deadlines and other commitments.

Understanding sponsors' work styles, strengths, and weaknesses is essential; having clear expectations of them is not enough. It takes ongoing effort to maintain the relationship. On a few occasions, we made the mistake of assuming our sponsors knew more about what was going on than they did. Keeping them up-to-date on project activities required regular injections of information. We managed this with weekly or biweekly meetings. We tried to keep these meetings brief and to the point. Sponsors also like to be kept informed about any problems or difficulties that may arise.

Some people resent consideration of such issues and complain about campus politics. Politics can indeed be troublesome, but if we view it as a function of how people function in a social system, it is a necessary consideration. Sensitivity to our own and others' work styles fosters optimal cooperation on the project.

\section{Step 4: Involve the Sponsor}

The more effort the sponsors put into a project, the more committed they will be to seeing it through. Thus, the project can be strengthened when administrators play a visible role.

Some of the possible ways the sponsors can support a project follow:

- Make a presentation to a funding agency.

- Add their names to a funding proposal.

- Send letters with their signature inviting faculty to become involved.

- Send letters with their signature to department chairs of faculty who will be involved.

- Attend a kick-off meeting and make a brief speech.

- Author a bylined short newsletter article. 
- Assign help (such as clerical or graduate assistants) that the project was unable to fund.

These are busy people, and their time is limited. One way to encourage their assistance is by helping them help us. We consider this homework an important part of collaborating with administrators. One sponsor provided letters inviting faculty to participate in the project. Another sponsor gave the brief opening speech setting out the challenge for the faculty in the two-week FLP seminar. We drafted the letter and outlined talking points the sponsors could adapt. While we could have sent the invitation under our own names and also given the kick-off speech, our sponsors had a much greater impact than we would have had. Also, sponsor involvement caused them to be more committed to the project. Since we had input regarding their messages, we were able to raise the probability that the right message was given at the right time. (See Middendorf, 1998 , for how to send appropriate messages at the right time.)

\section{Step 5: Evaluate Sponsors' Commitment}

When we want to find out how sponsors view a particular change, we need to interview them. We can ask them what is good and what is weak about the project. We use the interview not to talk ourselves, but to listen and learn. (See Appendix 20.1 for a sponsor rating form.) Do the sponsors view the project as useful, understand it fully, empathize with those targeted for a change? Will the sponsors commit resources as well as their own power and influence?

What do we do once we have rated the sponsors? Sponsors can be treated as change projects themselves. (See Middendorf, 1998, for facilitating the acceptance of change.) Sometimes it is necessary to find another sponsor, change the project based on input from the sponsor, or distance yourself from the project if failure seems certain (see Figure 20.1).

\section{Step 6: Recognize the Support of Sponsors}

Because the FLP is an ongoing development project, we wanted to ensure the continued collaboration and support of our sponsors. We have found three ways to reinforce their support: creating a culture of documentation, attracting media attention, and thanking them publicly.

Our sponsors have asked us several times for documentation and we have learned to make it a habit as part of furthering the successful relationship. Possible kinds of data include: 
Figure 20.1

\section{Evaluate Sponsor Commitment}

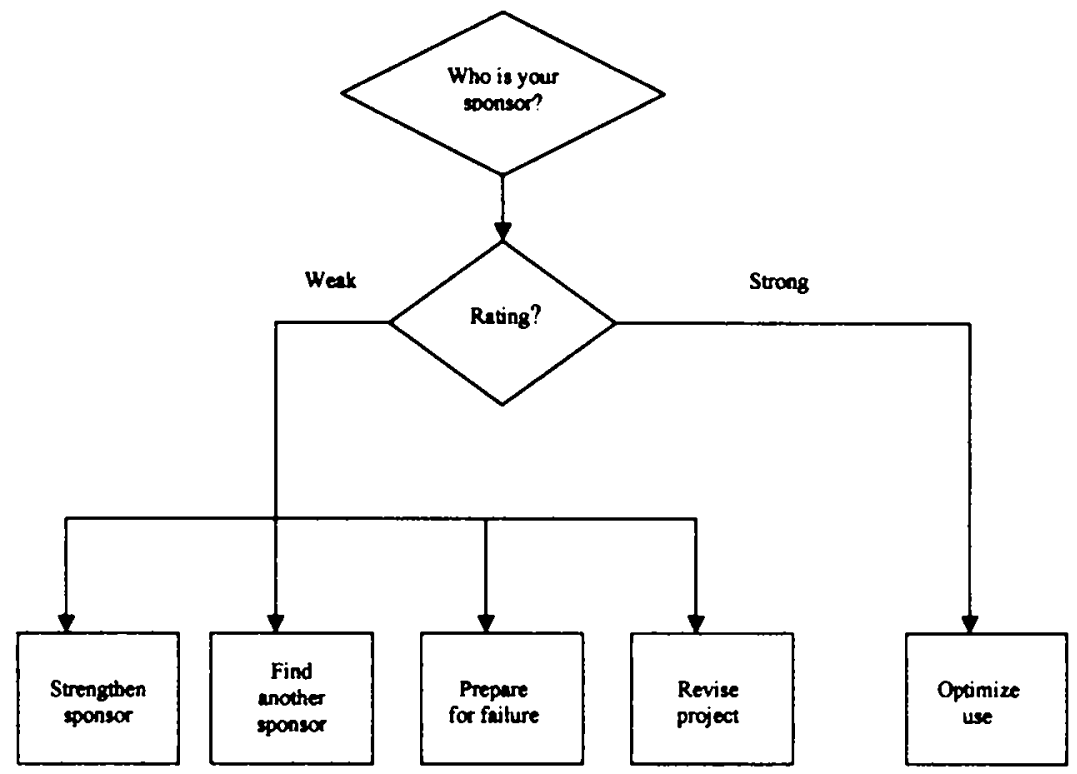

Adupted from Conner, 1993

- numbers of instructors successfully assisted

- numbers of projects completed

- continued use of services (repeat clients)

- numbers of undergraduates affected

- student retention rates

- student satisfaction with courses

We reported, for example, that over the first two years of FLP, 3,784 students were affected in classes the fellows were teaching. We provided sponsors with anecdotal evidence which they used in reports to their deans and the Board of Trustees. For example, one fellow said that the FLP experience "was the most intellectually stimulating two weeks of my 15-year career at Indiana University. I am very excited about introducing innovative teaching techniques to my classes. I learned that I can be a much better teacher than I am now."

To attract media attention, we solicited coverage of public FLP events 
by the local and campus newspapers and suggested that reporters interview sponsors. In a front page article of the local newspaper- "Faculty Seminar Produces Ideas Focused on Learning"-one sponsor was quoted, "This is part of a very big effort to think about learning on our campus." In the same article, a member of the Board of Trustees endorsed the FLP (Wright, 1998). Helping administrators get recognition in the media has proven beneficial to the project and reinforcing for the sponsors.

Finally, we thanked each sponsor at our end-of-year-celebration of our 1998 and 1999 seminars, by recognizing them and describing what each had contributed.

\section{SUMMARY}

Administrative support is crucial to the success of faculty development projects. The Freshman Learning Project was enhanced through strong sponsorship, which reinforced the importance of close administrator involvement. Our six-step model can help organizational and faculty developers manage administrative collaboration.

1) Know what the administrators need.

2) Identify likely supporters.

3) Maintain good working relationships.

4) Involve the sponsor.

5) Evaluate sponsors' commitment.

6) Recognize the support of sponsors.

By fostering collaboration with sponsors and other administrators, faculty development professionals can benefit from the knowledge, influence, and resources which link our efforts to campus priorities and decisions, thus improving the chances that our projects will be well-regarded and have greater chance for success.

\section{REFERENCES}

Conner, D. R. (1993). Managing at the speed of change: How resilient managers succeed and prosper where others fail. New York, NY: Villard.

Dormant, D. (1999). Implementing human performance technology in organi- 
zations. In H. Stolovitch \& E. Keeps (Eds.), Handbook of human performance technology (pp. 237-259). San Francisco, CA: Jossey-Bass.

Dormant, D., Middendorf, J. K., and Marker, A. W. (1997). Change mapping ${ }^{\text {SM }}$ participant guide. Bloomington, IN: Dormant and Associates.

Guskin, A. E. (1994). Restructuring the role of the faculty. Change, 26(5), 16-25.

Guskin, A. E. (1996). Facing the future. Change, 28 (4), 27-37.

Havelock, R. G., \& Zlotolow, S. (1995). The change agent's guide ( $2^{\text {nd }}$ ed.). Englewood Cliffs, NJ: Educational Technology Publications.

Kotter, J. P. (1985). Power and influence: Beyond formal authority. New York, NY: The Free Press.

Middendorf, J. K. (1998) A case study in getting faculty to change. In M. Kaplan \& D. Lieberman (Eds.), To improve the academy, 17, 203-224. Stillwater, OK: New Forums.

Middendorf, J. K. (2000). Finding key faculty to influence change. In M. Kaplan \& D. Lieberman (Eds.), To improve the academy, 18, 83-93. Bolton, MA: Anker.

Rogers, E. M. (1995). Diffusion of innovations ( $4^{\text {th }}$ ed.). New York, NY: The Free Press.

Wright, M. (1998, May 27). Faculty seminar produces ideas focused on learning. Herald Times, (A1, A7).

\section{Contact:}

Joan K. Middendorf

Director, Teaching Resources Center

Ballantine Hall, room 132

Indiana University

Bloomington, IN 47405-7701

(812) $855-2635$

(812) 855-6410 (Fax)

Email: middendo@indiana.edu

Joan K. Middendorf has been Director of the Teaching Resources Center of the College of Arts and Sciences at Indiana University for over a decade. She collaborates with faculty, instructors, and administrators to diffuse pedagogical innovations. In addition, she co-directs the Freshman Learning Project. As the designer of The Change Mappings Workshop, she has presented on leading change at more than 20 corporations. She publishes about college teaching and change in higher education. She studies T'ai Chi for relaxation and as an exercise in learning. 


\section{APPENDIX 20.1 \\ Getting Administrative Support for a Project}

1) What is your project?

2) Who might be appropriate sponsors?

3) How strong are your sponsors?

a. Does the sponsor believe this change will be useful?

$\begin{array}{lllllll}\text { Not at all } & 1 & 2 & 3 & 4 & 5 & \text { Strongly believes }\end{array}$

b. Does the sponsor understand the change?

$\begin{array}{lllllll}\text { Not at all } & 1 & 2 & 3 & 4 & 5 & \text { Fully understands }\end{array}$

c. Does the sponsor empathize with those who will have to make the change?

$\begin{array}{lllllll}\text { Not at all } & 1 & 2 & 3 & 4 & 5 & \text { Strongly empathizes }\end{array}$

d. Will the sponsor commit resources?

$\begin{array}{lllllll}\text { Not at all } & 1 & 2 & 3 & 4 & 5 & \text { Fully commits }\end{array}$

e. Will the sponsor support the change with power and influence?

$\begin{array}{lllllll}\text { Not at all } & 1 & 2 & 3 & 4 & 5 & \text { Strongly supports }\end{array}$

If your total is $\mathbf{2 0}$ or above, you probably have a strong sponsor. If your total is below 15, you may have a weak sponsor. If your total is $\mathbf{1 0}$ or below, and this is your major sponsor, you are likely to fail.

4) How well does the project meet sponsor needs?

a. How compatible is the project with institutional priorities? How much will it cost?

b. How will faculty and/or staff be involved with project planning? How will faculty and/or staff be involved with project implementation? 
c. In what ways will the project have an impact?

5) What do you need the sponsors to do?

Some of the possible ways the sponsors can support a project follow:

- Make a presentation to a funding agency.

- Add their names to a funding proposal.

- Send letters with their signature inviting faculty to become involved.

- Send letters with their signature to department chairs of faculty who will be involved.

- Attend a kick-off meeting and make a brief speech.

- Author a bylined short newsletter article.

- Assign help (such as clerical or graduate assistants) that the project was unable to fund.

6) How can you help the sponsors meet the needs of the project?

7) How will you reinforce and recognize their support so they are likely to collaborate again?

8) What documentation of project results can you provide? 
9) How will you gain media attention?

10) Where/when will you acknowledge their support? 